\title{
Diversification of old-age care services for older people: Trade-offs between coverage, diversification and targeting in European countries
}

Gerdt Sundström, ${ }^{1}$ Katharina Herlofson, ${ }^{2}$ Svein Olav Daatland, ${ }^{2}$ Eigil

Boll Hansen, ${ }^{3}$ Lennarth Johansson, ${ }^{4}$ Bo Malmberg, ${ }^{1}$ Maria Dolores

Puga González ${ }^{5}$ and María Ángeles Tortosa ${ }^{6}$

${ }^{1}$ Institute of Gerontology, Jönköping, Sweden

${ }^{2}$ Norwegian Social Research (NOVA), Oslo, Norway

${ }^{3}$ AKF (Danish Institute of Governmental Research), Copenhagen, Denmark

${ }^{4}$ Socialstyrelsen (The National Board of Health and Welfare), Stockholm,

Sweden

${ }^{5}$ Economics and Geography Institute of the National Research Council (CSIC),

Madrid, Spain

${ }^{6}$ University of Valencia, Spain

Correspondence to:

Professor G. Sundström Institute of Gerontology School of Health Sciences PO Box 1026, SE-55111

Jönköping, Sweden gerdt.sundstrom@hhj.hj.se

\begin{abstract}
Information on public services for older people is often limited to institutional care and Home Help/ Home Care, be it for individuals in surveys, statistics for a specific country or for international comparisons. Yet, these two major services in many countries are supplemented - or substituted - by other, minor services. The latter include services such as transportation services, meals-on-wheels, alarm systems, and day care. In this study the authors use various data sources to provide information on all or most of these types of support for Denmark, Norway, Sweden, Germany, England, Spain, and Israel, concluding with a closer scrutiny of Swedish service profiles. When all types of support are considered, service coverage in these countries is approximately $50-100 \%$ higher than for the two major types alone. Data suggest some degree of targeting, at least in countries with higher coverage rates for services. Coverage is estimated as a percentage of a specific age group which uses a service. In countries with lower coverage rates, users may demand or get what is available, with little differentiation between client needs. When user rates are high, there is also a greater overlap between family care and public services. In countries with lower coverage rates, family care and public services are more often substituted for each other. It is suggested that a range of services, major and minor, may suit the varying needs of older people more effectively than the choice between nothing, Home Help or
\end{abstract}

institutional care, but minor services also may be used as an inexpensive substitute for full support.

Keywords: Services, care, old age, Home Help, Home Care, Europe

\section{Introduction}

In most European countries public services for older people have developed stepwise, beginning with institutional care and then Home Help and home healthcare. Sometimes Home Help and home healthcare are two different services, sometimes a unified service (as is the case in Sweden, but not in Denmark and Norway). A myriad of other support services have consequently evolved, ranging from transportation to meals-on-wheels, alarm systems and day care. The latter are usually neglected in statistical reports and in research, and it is rare to find them discussed in a systematic way. An exception are recent articles in a Spanish newspaper about user statistics for the new Law on Dependency (where figures incorrectly equate episodes of service use with number of total beneficiaries). To properly monitor the development of services, experts have convened to 'clean up' statistics on provisions. ${ }^{1}$

Conventionally, low-level services (such as mealson-wheels and day care) often have been seen as 
minor ones and possibly not responding to the real needs of older people, although the importance of preventative services has been stated. ${ }^{2}$ 'That little bit of help' can refer both to these smaller services and to the value of providing just a little Home Help. For example, even a small amount of Home Help provides a window into older people's lives and may signal when other or more significant help is needed. But a minor service also may be more adequate in the sense that an alarm system for some people may provide more security than frequent visits by someone offering a Home Help service. It is probably natural for new services and technologies to be incorporated 'bit by bit' so that they successively complement or substitute for Home Help or family care. Examples are when meals-on-wheels complement, or substitute for, cooking done by a support worker or by the older person's family, and when a transportation service is provided to fetch food from a shop or to accompany an older person to the shop. In doing so, minor services may provide more flexibility for users, but may also mean a down-grading of the quality of the care: a common complaint about meals-on-wheels, for example.

In some countries (for example, Sweden) social service administrations strive to focus attention on Home Help users with more serious needs, sometimes symbolised through a name shift to Home Care, and try to discourage users with lesser needs through a stricter needs assessment, higher copayment rates or other ways of rationing. ${ }^{3}$ They may also provide minor services as an alternative to more intensive Home Care.

The major goals of this paper are to:

- map out the different mixes of major and minor services in selected European countries;

- assess how well needs are met under the different models of care;

- explore the implications for the family and the state of long-term care.

\section{Methods}

Secondary analysis of a number of earlier surveys was used to investigate the way in which services are allocated and who uses them. Data for Norway, England, Germany, Spain, and Israel were obtained from the cross-national OASIS project. ${ }^{4}$ The data collection was carried out in $2000 / 01$ among persons living at home in larger urban areas, aged 25 and over $(n=6,106)$. In this paper the analysis was restricted to the 1,988 persons aged 75 years and over. For Spain, data were used from a 2006 CIS survey $(n=3,335) .^{5}$ The Danish data come from Aeldredatabasen (Old Age Data Base), a survey that was carried out in $2007(n=3,693) .{ }^{6}$ Data for Sweden are threefold: data from the 2000 survey Hemma På Äldre Dar (At Home in Old Age, $n=1,466){ }^{7}$ data from the 2002/03 Level-of-living survey $(n=3,142){ }^{8}$ and municipality data from Jönköping (1999 and 2008). ${ }^{9,10}$ Samples, age groups, and time of data collection vary but this was not seen as an obstacle because the focus was on comparisons rather than exact estimates of coverage. With coverage (user) rates the authors mean the percentage of a specific age group who use a service. It is an advantage that it was possible to compare countries that differ considerably in their coverage rates of services and the way they overlap (or not), both for the individual services, for total coverage rates and family care.

\section{Results}

\section{Diversification: An International Panorama}

Table 1 shows user rates of Home Help/Home Care and other services for persons of advanced age $(75+)$ in five countries surveyed in the OASIS project. (In the OASIS project at risk was defined as being in the lower sixth percentile of the physical functioning scale of the Short Form $36 .{ }^{11}$ ) The findings indicate that coverage rates are much higher if all kinds of services are considered rather than

Table 1: Service use by older (75+) persons, 2001 (\%).

\begin{tabular}{|c|c|c|c|c|c|c|c|c|c|c|}
\hline & \multicolumn{2}{|c|}{ Norway } & \multicolumn{2}{|c|}{ England } & \multicolumn{2}{|c|}{ Germany } & \multicolumn{2}{|c|}{ Spain } & \multicolumn{2}{|c|}{ Israel } \\
\hline & All & At risk* & All & At risk* & All & At risk* & All & At risk* & All & At risk \\
\hline Home Care ${ }^{* *}$ & 35 & 66 & 28 & 39 & 11 & 16 & 10 & 13 & 42 & 50 \\
\hline Only other services $* * *$ & 21 & 18 & 17 & 19 & 9 & 10 & 13 & 16 & 32 & 28 \\
\hline No service use & 44 & 15 & 54 & 41 & 81 & 74 & 78 & 71 & 27 & 22 \\
\hline$N$ & 406 & 162 & 340 & 220 & 491 & 253 & 383 & 228 & 368 & 303 \\
\hline
\end{tabular}

Notes: *Defined as persons in the lower sixth percentile of activities of daily life (ADL) scale.

${ }^{*}$ Home Help and/or home healthcare and possible other services (common in Norway, England, and Israel).

***Alarm system and/or day care/centre, meals-on-wheels, transportation service, or any other service.

Source: OASIS survey, authors' own computations, sample aged 75+ living in the community in larger urban areas. 
those listed as Home Help/Home Care. This holds both for older persons in general and for persons at risk. The latter group is defined as having a functional ability below average (i.e. 'frail' persons). The intention with this distinction is to capture how well services target persons in need. User rates nearly double when all types of services are considered. Countries with higher rates - England, Israel, and Norway - also have a larger overlap between service types.

Table 2 extends Table 1 with the addition of more recent data for Denmark, Sweden, and Spain, which shows the same general pattern. In each country many more older persons in general and older persons at risk in particular are reached by services than suggested by gross average rates. This is especially the case with the high coverage country Denmark. Lower Home Care rates in Sweden and much lower rates in Spain are partly compensated for by extensive use of other services such as alarm systems, transportation services, and/or day care. Regrettably, surveys do not uniformly cover all types of services

\section{Targeting of Persons in Need}

The data presented above do not show in any detail the targeting of persons in need. Varying coverage rates raise the question of how well needs are being met. Table 3 focuses on users and non-users of services and whether they are at risk. Users of the more intensive services - Home Care - are mostly at risk, varying from $81 \%$ of users in Norway and Israel to $100 \%$ in Germany. These are services that provide household help and/or personal care. Persons who use only other, non-personal services are somewhat less needy, which is most noticeable in Norway and Israel (where remarkably many non-users still report needs in spite of the very high service levels seen in Table 1). The proportion of users of other services who are at risk ranges from $37 \%$ in Norway to approximately $75 \%$ in England, Germany, and Spain. Among non-users of any service, few (15\%) are at risk in Norway, with much higher rates about half or more - in the other countries. This suggests that there are large numbers of older people in the latter countries who have needs that are not being met by services.

The patterns also suggest that a high coverage country such as Norway differentiates more clearly among users of major and minor services than countries with lower coverage rates; Israel seems here to be a deviant case. In the low coverage countries Germany and Spain, but also England, there seems to be much less differentiation among users than in Norway.

If services were systematically targeted by need one would expect to find a clear gradient between level of needs and the amount and kind of services that are used or provided, and this is analysed in Table 4, using information for Denmark, Sweden, and Spain. Where available, surveys have collected reasonably comparable information on activities of daily life (ADL) functions and services.

High coverage countries Denmark and Sweden have a wide range of ADL capacity among users, ranging from hardly any ADL needs among nonusers of services; to some slight impairment among persons who use only other services; a clearly more impaired state for users of Home Care only; and an even more impaired state among persons using both Home Care and other services. The gradient is most evident in Sweden, with many older persons using other services only. In Spain, with low coverage rates, there is no discernible difference in needs, as measured by an ADL index, between these groups of (non)users.

Table 2: Service use by older* persons, 2002/03-07 (\%).

\begin{tabular}{lccrrrr}
\hline & $\begin{array}{c}\text { Denmark } \\
\text { All }\end{array}$ & $\begin{array}{c}2007 \\
\text { At risk }\end{array}$ & $\begin{array}{c}\text { Sweden } \\
\text { All }\end{array}$ & $\begin{array}{c}2002 / 03 \\
\text { At risk }\end{array}$ & $\begin{array}{c}\text { Spain } \\
\text { All }\end{array}$ & $\begin{array}{c}2006 \\
\text { At risk }\end{array}$ \\
\hline Home Care*** $_{\text {Only other services*** }}^{* *}$ & 18 & 84 & 8 & 54 & 5 & 21 \\
No service use & 11 & 5 & 9 & 23 & 7 & 16 \\
$N$ & 71 & 12 & 83 & 23 & 89 & 63 \\
\hline
\end{tabular}

Notes: *In Denmark 67, 72, 77, 82, and 87; in Spain and Sweden 65+.

$* *$ Persons who live alone and have one or more activities of daily life (ADL) needs.

***Home Help and/or home healthcare (and possible other services).

****In Denmark an alarm system, day care, and/or meals-on-wheels; in Sweden transportation services; in Spain an alarm system.

Source: Authors' own computations on 2007 survey Aeldredatabasen (Denmark), Level-of-living survey 2002-03

(Sweden), and 2006 CIS survey Condiciones de vida (Spain). 
Table 3: Percentage at risk* among users and non-users of services, 2001.

\begin{tabular}{lcccrr}
\hline & Norway & England & Germany & Spain & Israel \\
\hline Home Care** $_{\text {Only other services*** }}$ & 81 & 95 & 100 & 84 & 81 \\
No service use & 37 & 75 & 73 & 78 & 59 \\
All & 15 & 52 & 59 & 58 & 56 \\
$N$ & 43 & 63 & 65 & 63 & 67 \\
\hline
\end{tabular}

Notes: *Defined as persons in the lower sixth percentile of activities of daily life (ADL) scale.

${ }^{* *}$ Home help and/or home healthcare and possible other services (common in Norway, England, and Israel).

***Alarm system and/or day care/centre, meals-on-wheels, transportation service, or any other service.

Source: OASIS survey, authors' own computations, sample aged 75+ living in the community in larger urban areas.

Table 4: Older persons* by service use and average ADL index, ${ }^{* *} 2000-07(\%)$.

\begin{tabular}{lccc}
\hline Service use & Denmark & Sweden & Spain \\
\hline No service use & 8.7 & 8.3 & 5.9 \\
Only 'other services'*** $^{*}$ & 8.5 & 7.4 & 5.0 \\
Only Home Care & 7.5 & 6.9 & 5.4 \\
Home Help care and & 6.0 & 4.8 & 5.4 \\
$\quad$ 'other services' & & &
\end{tabular}

Notes: *In Denmark 67, 72, 77, 82, and 87; in Spain and Sweden $75+$.

${ }^{* *}$ Here defined as the number of activities of daily life (ADL) a person can do without help for the following: shopping, cooking, cleaning, laundry, (un)dress, get into/ out of bed, shower/bath, toileting, go outdoors without personal help. The index can thus vary from 0 to 9.

***In Denmark an alarm system, meals-on-wheels, and/or day care; in Spain an alarm system; in Sweden transportation services.

Source: Authors' own computations on 2007 survey (Denmark), Hemma På Äldre Dar survey 2000 (Sweden), and 2006 CIS survey Condiciones de vida (Spain).

This finding suggests there may be other sources of support for high level, unmet needs in Spain.

\section{State, Family, and Older People in Need}

Table 5 analyses support from the family and the state, respectively. Public services are defined in the same way as above (Home Help and/or home healthcare and/or other potential services). In
Norway and Israel, countries with high coverage rates, a substantial proportion of older people at large (31\% and $47 \%$, respectively) and persons at risk as well, only depend on public services while less than one in ten depend only on their families (there are many more than one in ten who depend on families altogether). In countries with lower coverage rates, many more are helped only by family. Mixed support, from both family and the state, is common, but has an intermediate position in Norway and Israel, and is the most common alternative in England. In Germany and Spain, few have this mixed support, suggesting that in low coverage countries the choice is between family or the state. Persons at risk are rarely left unsupported by family and/or the state in high-coverage countries (such as Israel and Norway), although some may (also) use private, paid help which is common in Germany, Spain, and Israel. The analysis suggests that the greater the need, the more help is provided by both family and the state, a pattern which is more common in high coverage countries.

\section{Sweden: A Case Study of Diversification of Services}

Sweden was early (1950s) in establishing traditional Home Help, and later in providing other services such as transportation, day care, mealson-wheels, alarm systems etc. Statistics on these

Table 5: Service use and family support for older persons, 2001 (\%).

\begin{tabular}{|c|c|c|c|c|c|c|c|c|c|c|}
\hline \multirow[b]{2}{*}{ Support type } & \multicolumn{2}{|c|}{ Norway } & \multicolumn{2}{|c|}{ England } & \multicolumn{2}{|c|}{ Germany } & \multicolumn{2}{|c|}{ Spain } & \multicolumn{2}{|c|}{ Israel } \\
\hline & All & At risk & All & At risk & $\overline{A l l}$ & At risk & All & At risk & All & At risk \\
\hline Public only** & 31 & 46 & 17 & 21 & 12 & 15 & 9 & 12 & 47 & 49 \\
\hline Public and family & 20 & 37 & 23 & 33 & 6 & 9 & 7 & 9 & 18 & 22 \\
\hline Family only ${ }^{* * *}$ & 9 & 4 & 18 & 19 & 28 & 31 & 31 & 37 & 7 & 6 \\
\hline Neither & 40 & 13 & 42 & 27 & 54 & 45 & 54 & 42 & 29 & 22 \\
\hline$N$ & 406 & 162 & 340 & 220 & 491 & 253 & 383 & 228 & 368 & 303 \\
\hline
\end{tabular}

Note: *Defined as persons in the lower sixth percentile of the ADL scale.

**Home Help and/or home healthcare and/or possible other services.

***Family and/or other informal carers.

Source: OASIS survey, authors' own computations, sample aged $75+$ living in the community in larger urban areas. 
other services - where they exist - are seldom used in a systematic way, but suggest a trend towards diversification of services for older people, schematically illustrated in Figure 1.

In Sweden in 1950 only institutional care was available, and then to $6 \%$ of those aged $65+$ (in fact the same user rate as in 2008). After the great expansion of Home Help in the 1950s and 1960s, the total coverage rate for institutional care and Home Help culminated at $25 \%$ of the $65+$ age group in about 1975, followed by a period of drastic cutbacks in access to institutional care and Home Help. If other services are included, approximately $25 \%$ of older persons in 2008 were covered by one or more services; that is, the same total coverage rate as in 1975. Sometimes these other services overlap with Home Help, but often they do not. Most users of Home Help also use some other service, but many users of other services do not use Home Help.

Many countries strive to provide their services efficiently, which usually means not providing unnecessary help, avoiding duplication, giving the right kind of help and the right volume of help. A general assumption is that the more diverse the range of services offered the better, because needs differ and they change over time. To add some insight into this issue, selected data on public service use in Sweden were drawn upon.

Data on the overlap of different services capture how the range of services are used, and whether services target more older people than just the individual services alone. At best they may also suggest whether they do it in a rational way; that is, differentiate clients by need. The most common social service for older Swedes, and often their first contact with the helping bureaucracy, is transportation services. In total some $18 \%$ of older people use this service, which is very extensive in Sweden. Persons entitled to use the service just call an ordinary taxi and pay the same

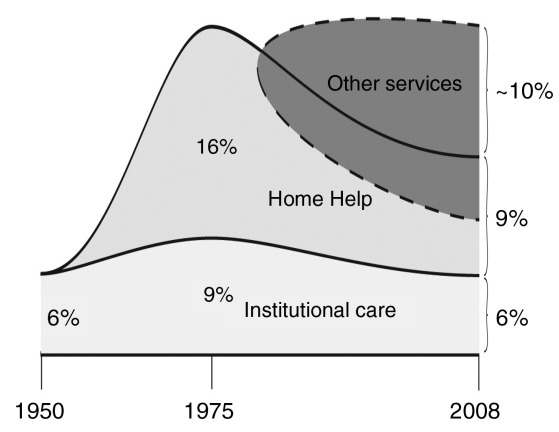

Figure 1: User rates of services for older people $(65+)$ in Sweden 1950-08 (\%).

Source: Authors' own computations from statistics on services, government investigations, and survey data. fee as if they had been able to take the local bus/ tram. If they are severely handicapped, there are also special vehicles available that take wheelchairs etc. Somewhat less common are meals-on-wheels, alarm systems etc. None of these services were available in the early 1970s. Official statistics covered only Home Help and institutional care up to 2008, but actual coverage and overlaps can be identified by examining surveys which have probed use of various services. Figure 1 indicates that increased diversification of services has allowed Sweden to cover the same proportion of older people with services today as in 1975 by augmenting the lower volume of Home Help and institutional care with an increase in other services. There is thus no decline in total coverage rates if the whole service profile is considered.

A close-up look at shifts in services is provided by data for the single Swedish municipality of Jönköping (population 122,000) where coverage rates for Home Help and institutional care are about the national average. The municipality has provided data from its exhaustive, computerised records on older clients. The authors' elaborations on these data are shown in Table 6, which gives an idea of how services have evolved over the last decade. There has been both change and overall continuity in provision of the different kinds of services. As it gets very complicated to account for all combinations, the data have been simplified into a few categories.

Service access in total in the Jönköping municipality between 1999 and 2008 has been stable, but there has been considerable change in the kinds of services provided. Some of the more intense and expensive services have been supplanted by less costly ones: institutional care by Home Help, and Home Help in turn by other services (transportation services, meals-on-wheels, and/or alarm systems etc.). Before the age of 80 , these other services are the most commonly accessed.

It is worth mentioning that the complete panorama of public support is not known, as there is a separate organisation that provides home visits by district nurses, sometimes overlapping with municipal public services, sometimes not. Special analyses for this study on national data indicate that approximately $7 \%$ of older Swedes living in the community receive such home visits but do not use Home Help, suggesting even higher user rates than the ones indicated here, although the overlap with other services is not known.

The quality of the services cannot be assessed with these data, but how well they are targeted to needs is indicated in a national sample of Swedes aged 75+ 
Table 6: Older people's service use, Jönköping 1999 and 2008 (\%).

\begin{tabular}{|c|c|c|c|c|c|}
\hline Age & Any kind of service* & Home Help & Institutional care & Only 'other' service & No service \\
\hline $65-74$ & 7 & 2 & 1 & 4 & 93 \\
\hline $75-79$ & 18 & 6 & 3 & 9 & 82 \\
\hline $80-84$ & 37 & 12 & 9 & 16 & 63 \\
\hline $85-89$ & 62 & 23 & 17 & 32 & 38 \\
\hline $90-94$ & 80 & 27 & 34 & 19 & 20 \\
\hline $95+$ & 82 & 24 & 47 & 11 & 18 \\
\hline \multicolumn{6}{|l|}{2008} \\
\hline $65+$ & 23 & 8 & 6 & 9 & 77 \\
\hline $80+$ & 53 & 18 & 17 & 19 & 47 \\
\hline \multicolumn{6}{|l|}{1999} \\
\hline $65+$ & 24 & 7 & 8 & 9 & 76 \\
\hline $80+$ & 54 & 16 & 22 & 16 & 46 \\
\hline
\end{tabular}

Notes: *Institutional care, Home Help, day care, alarm system, transportation service, and/or meals-on-wheels or any other public service provided under the 1982 Social Service Act.

Source: Calculated on information provided in November 2008 by Pia Kopp, Jönköping Municipality and information provided in November 1999 by Anette Elver, Jönköping Municipality.

shown in Table 7 (expanding on Table 4). Persons who use no public service tend to be in good health, persons who use other services usually only have minor needs for help. The more services users receive, the worse their ADL status. A closer scrutiny of the survey also reveals that persons who use Home Help and get more hours of help have a worse ADL status.

\section{Discussion}

When the often overlooked minor services were included, in many European countries it was

Table 7: Older persons $(75+)$ by service use and ADL index, Sweden 2000 (\%).

\begin{tabular}{lc}
\hline $\begin{array}{l}\text { Type of public service used by older } \\
\text { persons living in the community }\end{array}$ & $\begin{array}{c}\text { ADL index, } \\
\text { average* }\end{array}$ \\
\hline No service use & 8.3 \\
Only transportation service & 7.5 \\
Only alarm system & 7.5 \\
Transportation service and alarm & 7.2 \\
$\quad$ system & 6.9 \\
Home Help only & 5.8 \\
Home Help and transportation & \\
$\quad$ service & 5.5 \\
Home Help, transportation service, & \\
$\quad$ and alarm system & 3.8 \\
Home Help, transportation service, \\
$\quad$ alarm system, and meals-on- \\
$\quad$ wheels
\end{tabular}

Notes: * Here defined as number of activities of daily life (ADL) that a person can do without help for the following: shopping, cooking, cleaning, laundry, (un)dress, get into/ out of bed, shower/bath, toileting, go outdoors without personal help. The index can thus vary from 0 to 9 . Some $51 \%$ managed all nine activities without problems. Source: Authors' own computations on the Hemma På Äldre Dar survey 2000. possible to add $50-100 \%$ to coverage rates based on administrative statistics or survey data on Home Help/home healthcare and institutional care. A strength of the analyses is that the data refer to actual user rates, not to abstract rates such as number of beds per thousand older people or similar indicators. The data presented in this paper suggest that countries with higher service levels target all their services more strictly by needs than countries with lower service levels. Surprisingly, countries with low service levels, for example, Germany and Spain, tend to differentiate services less according to needs than countries with higher service levels, for example, Denmark and Sweden. Public services often overlap with family care in countries with high service levels, such as the Nordic countries. In countries with more 'familistic' policies - where families are seen as the primary resource of help and care - and less access to services, for example, Germany and Spain, public services such as Home Help and other services are often substitutes for informal care.

It thus appears that countries with lower user rates differentiate less clearly between users at different levels of need. It is possible that, when coverage is limited, administrators provide what they have, and older people may limit their demands to what is available. Such is suggested as the case in Spain, where many family members now receive financial compensation rather than services which may be lacking especially in rural areas, a trend that has irritated private service providers. ${ }^{1}$ Also in countries with higher service levels it is common that access to support other than public services is considered to be an option by administrators and users. When many older persons use no 
public services, or services which do not differentiate clearly by need, they may use family and/or privately purchased help to complement public sources of support.

The gradual diversification of service provisions, with the ensuing shift in the service profile, may be seen as a response to the rising costs of providing Home Help and institutional care, but may also be a response to the diversity of needs among older people and an attempt to satisfy needs previously not acknowledged. Depending on the concrete outcome for individual older persons, these new services and new ways to assess needs may mean a deterioration of overall service, but the opposite interpretation is also possible. These other services may be as adequate, or more, than the more traditional Home Help. An older person living in the community who may be compromised by insecurity or dizziness, for example, may be better served by an inexpensive alarm system than by infrequent visits by a Home Helper. Some of the newer services may even impart more autonomy than the Home Help service. The most visible example in Sweden is the transportation service. Previously the Home Helper would bring food shopping or (less commonly) take a walk with the user of the service to the shop to do the shopping. In contrast, the transportation service gives freedom in terms of timing and destination. A limitation of this analysis is that it is not known whether the provided services are appropriate for users' needs, an issue that future studies should consider.

The minor services that reach a great number of older people may be important and help the user to manage longer at home. ${ }^{2}$ It is therefore unwise to ration services through targeting fewer people with more intensive support, and leaving the rest with no services. Minor services, including small amounts of Home Help, are often inexpensive, but may have a significant preventative function. A still controversial issue is whether the new minor services serve the diverse needs of older people better than the more rigid choice between Home Help and institutional care for a more select group. Minor services may also be (mis)used as less expensive, but inferior, substitutes for the real thing. Both of these interpretations are possible, and deserve further exploration. One step in that direction is that producers and users of statistics and surveys improve their data by considering all types of services and also report the proportion of older people who use any service.

\section{Acknowledgments}

Part of this research has been supported by a research grant to Hitotsubashi University from the Ministry of Education of Japan (grant number 18002001). Some of the results were presented at a workshop in Tokyo in January 2009, and some at the World Congress of Gerontology in Paris 2009. Significant data were kindly provided by Anna Hagman, Socialstyrelsen (The National Board of Health and Welfare) and by the social service administration, Jönköping municipality. The authors are grateful to the reviewer of an earlier version of this manuscript.

\section{References}

1. Morán C. The law on dependency finances irregularly thousands of users. Three years after the law we still don't know the number of users. Many users are recorded two or three times. El Pais. 14 September 2009; Morán C. The authorities 'clean' the statistics on dependency. El Pais. 22 September 2009.

2. Clark H, Dyer S, Horwood J. That little bit of help. The high value of low level preventative services for older people. Bristol: The Policy Press and Joseph Rowntree Foundation; 1998.

3. Sundström G, Tortosa MA. The effects of rationing Home Help services in Spain and Sweden: a comparative analysis. Ageing Soc. 1999; 19: 343-61.

4. Lowenstein A, Ogg J (eds.) Oasis. Old age and autonomy - the role of service systems and intergenerational family solidarity. Final report. Haifa: The University of Haifa; 2003. See also Daatland SO, Herlofson K. Lost solidarity or changed solidarity: a comparative European view of normative family solidarity. Ageing Soc. 2003; 23: 537-60; and Daatland SO, Lowenstein A. Intergenerational solidarity and the family-welfare state balance. Eur J Ageing. 2005; 2: 174-82.

5. Condiciones de vida. 2006.

6. Aeldredatabasen. 2007.

7. Hemma På Äldre Dar. 2000.

8. Level-of-living survey. 2002/03.

9. Jönköping. 1999.

10. Jönköping. 2008.

11. For more information on the Short Form 36, see: Ware JE, Sherbourne CD. The MOS 36-item short-form health survey (SF 36). Med Care. 1992; 30: 473-83. 


\section{Author Information}

Gerdt Sundström is professor of social work at the Institute of Gerontology, School of Health Sciences, Jönköping, Sweden. He has researched public services for older people, in the Nordic countries and internationally, with recent studies on local variations in services, family care in Europe and demography of ageing in the Nordic countries. He is also a consultant for the Swedish Association of Retired Persons (SPF).

Katharina Herlofson is a $\mathrm{PhD}$ student (sociology) at Norwegian Social Research (NOVA), Oslo. Her main research interest is intergenerational family relations and she was on the research team of the EU project OASIS (Old age and autonomy - the role of service systems and intergenerational family solidarity). She is currently involved in the EU project Multilinks and the Norwegian 'Life course, Ageing and Generations' (NorLAG) study.

Svein Olav Daatland is a social psychologist and a senior research fellow at NOVA, Oslo. He has served as a research director at NOVA and his work has been published widely on ageing, intergenerational solidarity, and care. He was the Norwegian partner for the OASIS project and has coordinated Nordic comparative studies on ageing and services for older persons, including the NorLAG study.

Eigil Boll Hansen is an associate professor at AKF (Danish Institute of Governmental Research), Copenhagen. He has researched living conditions of older people and their housing, use of healthcare and services. A special focus has been the provision of services and the wellbeing of users.
Lennarth Johansson is a psychologist and senior researcher at Socialstyrelsen (The National Board of Health and Welfare), Stockholm. He has worked for a considerable time on efforts to improve public services for older persons and their families. Presently he is working on the implementation and evaluation of new legislation on carers' rights to support.

Bo Malmberg is a professor and head of the Institute of Gerontology, School of Health Sciences, Jönköping. He has a background in education and psychology and has primarily worked on social psychological issues in ageing, health, and old-age care, including gender differences. He is also adjunct professor of health and human behaviour at Pennsylvania State University.

Maria Dolores Puga González is a geographer and senior researcher at the Economics and Geography Institute of the National Research Council (CSIC), Madrid. She has researched health and disability, residential strategies, family structures, demography of ageing, and intergenerational transfers. She has also done commissioned work for government agencies. At the time of publication she works at the social research centre Colegio de Mexico.

María Ángeles Tortosa is a senior lecturer in the Applied Economics Department of the University of Valencia. With a background in economics she has researched public and private healthcare, and services for older people. She has been active in the Valencia University 'Education for Seniors' programme and the Valencian Association of Geriatrics and Gerontology. 